\title{
GENDER INEQUALITY IN MUSLIM-MAJORITY COUNTRIES: MYTHS VERSUS FACTS
}

\author{
Nezahat DOĞAN \\ (Received: 19 August 2014; revision received: 16 January 2105; \\ accepted: 20 January 2015)
}

The study uses a cross-sectional data set for 209 countries in order to test whether the regulation of social life by Islamic norms and values is related to gender inequality and whether the impacts differ for the MENA countries, as well as Arab- and Muslim-majority countries. The study finds that the impact of gender inequality differs for the MENA, Arab- and Muslim-majority countries only when control variables are excluded from the regressions. The paper obtains empirical evidence against the belief that religion and oil are culprits responsible for holding women back in Muslim countries.

Keywords: gender inequality, MENA, ICT, institutional quality, economic growth, religion, Muslim, Islam

JEL classification indices: D63, O15

\section{INTRODUCTION}

Gender inequality and disparities between males and females have serious social cost implications. More importantly, they are negatively affecting the human and economic development in the form of more poverty, less economic growth, bad governance, and lower level living standards (World Bank 2003).

\footnotetext{
Nezahat Doğan, Assistant Professor and Acting Dean at the Faculty of Economics, Administrative and Social Sciences, British University of Nicosia (BUN), Ozankoy/Kyrenia/T.R. Northern Cyprus, Turkey. E-mail: nezahat.dogan@bun.edu.tr
} 
Our main focus is the Middle East and North Africa (MENA) region. The study considers Arab countries as a subgroup and Muslim countries in a broader sense. According to the World Bank reports for MENA $(2004,2012)$, there is a paradoxical situation in terms of gender equality and development. Most countries increased women's education and health level through investments in social sectors. However, these improvements are not reflected in the level of female labour force participation rate and growth as much as expected. With these proportions, the MENA countries would need 150 more years to catch up current world average (World Bank 2012: 3). According to Abdelali-Martini (2011), the main reason behind the low level of female labour force participation rate is that staying at home instead of work for women is regarded as a symbol of prestige in this part of the world.

Research on gender equality became more popular after the Arab Spring. The studies analysing gender equality from an Islamic perspective argue that Muslim countries still have some cultural and political drawbacks affecting equality within society (Fish 2002; Inglehart - Norris 2009). Therefore, Brotman et al. (2008) suggest understanding the role of political Islam (Law of Islam) before understanding the policy or traditional culture in this region.

In our opinion, gender inequality in a country may not be directly attributed to Islam. When we consider to what extent Muslim countries apply religious laws, there is diversity in the region. The Gender Inequality Index (GII) shows significant variation across countries with a similar Muslim population percentage. For instance, Tunisia with a Muslim population ratio of $97 \%$ has a GII of 0.515 , while Afghanistan with a similar Muslim population ratio (98\%) has a much worse gender equality, with a GII value of 0.797 . Therefore, it can be argued that the Muslim ratio should not be taken as an explanatory variable or direct measure of gender inequality. The Arab Human Development Report 2005 published by the United Nations Development Programme (UNDP) entitled "Towards the Rise of Women in the Arab World" uses a capabilities approach to analyse the status of women. The report emphasises that the status of women has many dimensions linked to cultural, religious, socioeconomic, legal, and political components.

Our study contributes in four ways to the existing studies. (1) GII is used to cover more than one dimension of gender equality. Previous studies used labour force activity rates of females and average years of schooling for females separately as a measure of gender inequality in employment and education, respectively. (2) The paper uses the infocommunication technology (ICT) index and the institutional index as explanatory variables, which are broadly considered in the literature from both pessimistic and optimistic points of view. (3) The impact of religion and oil on gender equality is also tested. (4) The paper avoids the simple use of dummy variables in order to estimate the impact of Islamic religiosity. 
Dummy variables are poor substitutes for more analytical models and incorrect inferences may arise when the binary classification is not suitable. In order to measure the impact of religion, two different regressions were used in terms of the religion-related explanatory variables, which are the Muslim ratio and the social regulation of religion index. In each regression, variables such as the purchasing power parity (PPP) adjusted per capita income, average years of schooling, and dummies for the MENA region, oil exporters, Arabs, and Islam are used as control variables.

The rest of the paper is organised as follows. Section 2 introduces the underlying economic theory. Section 3 and 4 explain the data, the empirical model, and the estimation methodology. In Section 4, the empirical results are presented. Finally, Section 5 concludes the paper.

\section{ECONOMIC THEORY ON GENDER EQUALITY, ICT, AND INSTITUTIONAL-SOCIAL INFRASTRUCTURE}

In the literature, religious practices and gender relations have been examined by several studies and it is generally concluded that Islam is a reason for persistent gender inequality. For example, Fish (2002) analysed the impact of Islam on literacy rate, sex ratio, women's political participation, and gender empowerment measure (GEM) by using cross-section data and concluded that overall, the status of women in Muslim countries is inferior compared to non-Muslim countries. However, Fish explained that the only reason for this result is the democratic deficit in these countries. Donno - Russett (2004) concluded that the effect of Islam is much stronger and consistent in Arab countries. Noland (2005) reached a similar conclusion and explained the autocratic nature of countries with higher Muslim population as a reflection of being Arab rather than Islamic. According to Inglehart - Norris (2009), the reason for the cultural conflict between Islamic countries and the West is not their political system (democracy), but gender equality. They found that Muslim societies are significantly less supportive on equal opportunities and rights for women.

Rauch - Kostyshak (2009) analysed the gender gap in education and labour force participation. They used the Muslim percentage of a country's population as an explanatory variable and found that the gender gap in 100\% Muslim countries is $18.3 \%$ higher than in a country with a $0 \%$ Muslim population share. However, when they added a dummy variable for Arab countries, the significance of the Muslim ratio declined. They concluded that the Arab effect explains the Islamic effect (p. 182). According to their suggestion, if it is not the Islamic effect, there are two reasons for explaining the results: social pressure on married Arab 
women due to the common belief that they should be supported by husbands, and very strong beliefs and expectations for mothers to continue their careers as mothers at home.

Another important issue is that most countries in this region are oil-exporting countries, and the oil sector is classified as a male-dominated sector, which discourage women to enter the labour market (Moghadam 2004; Ross 2008). This argument is used in the literature when explaining the reason for the low-level labour force participation rate of females. Ross (2008) used cross-national regressions on the female labour force by using oil rents per capita as an explanatory variable, with some other control variables such as income, income squared, working age, Islam as a share of Muslims, dummy for MENA, and dummy for communist states. The results showed that the Islam does not have an effect on the female labour force, while oil rents have a significant negative impact on the female labour force. However, the World Bank compared Egypt and Indonesia in the 2012 MENA report and concluded that even if these countries have similar oil reserves, diversification in exports and the potential for employing females, the female labour force participating rate in Egypt is half of that in Indonesia. This suggests that we have to use some other variables rather than religion or oil for explaining the gender inequality or gender gap.

Another concept used in this study is the impact of the the infocommunication technology (ICT) revolution. One of the major questions in the literature, both on theoretical and empirical grounds, is whether ICT can help to improve gender equality. Women who have limited opportunities for participating in social and economic life due to some constraints such as time and socio-cultural norms may become more active by using ICT applications and ICT tools. A second group of scholars assumes that technology is gendered because it is developed and shaped by society. In turn, however, technology affects society as well (Hodgkinson 2000; Wajcman 2009). Lohan - Faulkner (2004) classified the feminist studies on technology as "women in technology" studies, and "women and technology" studies (p. 320). While women in technology studies generally focused on the reasons of there being fewer women in technology-related occupations, women and technology studies developed two opposite approaches to the outcomes of technology, namely the optimistic and pessimistic approach. According to the results of a study conducted about the impact of ICT expansion in the Middle East region for the period of 1995-2003 by Shirazi (2008), the expansion of ICT decreases the digital divide and promotes democracy and freedom in the region. 


\section{DESCRIPTION OF THE DATA}

The focus of this study is to investigate the impact of religion, institutional quality, and ICT on gender equality. Cross-sectional estimation is used for $209^{1}$ countries for the year 2008 to investigate (1) the impact of the Muslim ratio, Islam, and oil on the gender equality, especially for the MENA region, while controlling for (2) the impact of per capita income as a proxy for the level of economic development, (3) the impact of ICT on gender equality, and (4) the impact of the institutional and social infrastructure.

The econometric estimation uses the gender inequality index (GII) as a measure of gender equality. GII is developed by the United Nations and based on three dimensions of gender inequality, with five indicators: (1) labour force participation, (2) secondary level and higher educational attainment, (3) parliamentary representation, (4) adolescent fertility ${ }^{2}$ and (5) maternal mortality ${ }^{3}$. GII ranges from 0 (no inequality) to 1 (complete inequality). GII data is collected from the United Nations database.

Another variable used in this study is the institutional quality index that includes the Political Risk Service (PRS) Group's six indicators, which are (1) Bureaucratic quality, which shows the quality and strength of bureaucracy as a shock absorber, (2) Composite risk rating, which shows the political, economic, and financial risk rates of the countries, (3) Corruption, which is the failure of the governance in the economic, financial, and political environment, (4) Democratic accountability, which shows the responsiveness of the government to its citizens as well as the free and fair elections of the government, (5) Government Stability, which shows the ability of the government to stay in office and manage its programmes, and (6) Law and order, which shows the strength of the legal system and the practice of complying with laws. Since all six measures are highly correlated, an index of institutional quality (INSTQ) is constructed from the underlying six series using principal components analysis.

Our ICT index (ICTI) is constructed by using six measures of access and density. These are (1) number of computers per 100 persons, (2) number of internet users per 100 persons, (3) number of telephones per 100 persons, (4) ICT expenditure as a share of GDP, (5) ICT expenditure per capita, and (6) mobile

1 Although there are 209 countries in our sample, the number of observations in each regression varies because of missing values in the variables entering the regression equations.

It is defined as "number of births to women ages 15-19" (UNDP 2010: 232).

According to UNDP(2010: 233), maternal death is defined as "the death of women while pregnant or within 42 days after terminating a pregnancy due to any cause related to or by pregnancy not due to accidental or incidental causes". 
subscribers per employee. All ICT variables in this study are collected from the ICT indicators of International Telecommunication Union.

In both regression specifications, the PPP adjusted per capita income and the total average years of schooling for age $15+$ are used as additional control variables. The precise definition of all variables is given in the Appendix.

The GII is computed for the year 2008. Other variables are averages over 2000-2008. Taking averages over a longer span for the other variables increases the number of observations available in the regression, but more importantly incorporates the lagging impact of education, institutional quality, and ICT. ${ }^{4}$

\section{OUR METHODOLOGY}

The empirical estimations are carried out in a cross-country framework due to data limitations. ${ }^{5}$ The dependent variable, the gender inequality index (GII), used in this study is more comprehensive and incorporates more dimensions of the complex gender inequality structure. Several variants of the following basic cross-section regression specification are estimated:

$$
\log \left(\mathrm{GII}_{i}\right)=\mu+\log \left(\text { MUSTRATIO }_{i}\right)+\gamma^{\prime} \log \left(X_{i}\right)+\varepsilon_{i}
$$

where $i$ denotes the country.

$\begin{array}{ll}\text { GII } & =\text { Gender Inequality Index } \\ \text { MUSRATIO } & =\text { Muslim population/total population } \\ \text { X } & =\text { vector of control variables } \\ \varepsilon & =\text { error term. }\end{array}$

Control variables include the following:

ICTI $\quad=$ ICT Index created by using factor analysis

4 Results are qualitatively the same when only 2008 data is used, but several parameters estimated become insignificant and estimates lose their precision due to the increased number of missing values.

5 Our research question is examined by using a mixture of nominal, ordinal interval and ratio variables. The methodology we use in the study has been extensively used in the empirical literature in economics, political science, and sociology as well as in many other social sciences. Moghadam (2004), World Bank (2004), Ross (2008), and Rauch - Kostyshak (2009) also made inferences about gender equality in the Middle East or the Muslim countries using an analogous regression approach. 
INSTQ = Institutional Quality Index created by using factor analysis ${ }^{6}$ PPP2010 = PPP adjusted per capita income.

The following dummy variables are defined in order to examine the impact category they relate:

$\mathrm{ARAB}=1$ for Arab countries, 0 for others

ISLAMIC $=$ dummy to measure to what extent a country is Muslim, it is defined as 1 if MUSRATIO $>0.75,0$ otherwise

MENA $=1$ if the country is in the MENA region, 0 otherwise

OIL $=1$ if the country is a major oil exporter, 0 otherwise.

The second specification uses the social regulation of religion index (range between $0-10$, lower is less regulation) as the independent variable to check the robustness of the results.

The second cross-section regression is specified as follows:

$$
\log \left(\mathrm{GII}_{i}\right)=\mu+\log \left(\mathrm{MSRI}_{i}\right)+\gamma^{\prime} \log \left(X_{i}\right)+\varepsilon_{i}
$$

where

MSRI = social regulation of religion index (range between $0-10$, lower is less regulation) and other variables are as defined for Eq. (1).

Thus, four dummies are used to capture the regional and religion effects in order to examine the interaction of ARAB, ISLAMIC, MENA, and OIL categories with the measure of the extent of religiosity. The interaction dummy indicates whether the category it represents has an impact on gender inequality beyond and above the average impact of the religiosity measures MUSRATIO or MSRI. If, for instance, the coefficient of the interaction term MUSRATIO*ARAB is positive and significant, it means that the negative impact of religiosity on gender equality is greater than in other countries. Religion-related data are collected from "The Association of Religion Data Archives".

In studies involving the impact of religiosity, a dummy variable is often added to distinguish between Muslim and non-Muslim countries, or MENA countries and non-MENA countries to control for differences between the two categories, ceteris paribus. In this study, such use of dummy variables to measure the impact of Islamic religiosity on gender equality is avoided. Instead, it uses MUSRATIO and MSRI, which indicates the extent of Islamic regulation in a country. Dummy variables are only used to control for Muslim dominance (a country with more

6 The principle components analyses for ICT variables and institutional variables are available upon request from the author. 
than $75 \%$ Muslim population), Arab, and MENA effects, but not for measuring the impact of Islamic religiosity on gender equality. There is a rising trend in the literature (see Jacobsen - Newman 1995) to use dummy variables to control for gender differences, while the study of interactions with other variables such as race has decreased. There are two major problems with the use of dummy variables in order to distinguish between Muslim and non-Muslim countries. First, a dummy variable that classifies a country as Muslim does not differentiate on the extent of religiosity: Saudi Arabia and Turkey, for instance, are classified as the same. Second, the traditional way of using dummy variables in the gender equality regression is useful for quantifying discriminatory outcomes, but they do not provide a comprehensive analysis on the discriminatory process and the causes of the discriminatory outcome.

\section{EMPIRICAL RESULTS}

First, simple regressions estimation results are presented in Table I. Simple regressions of GII on MUSRATIO and MSRI illustrate the likely misleading results that may arise from misspecified regressions. Simple regressions are also estimated on dummy variables in order to serve as a benchmark for comparing the results and showing the outcome of possible specifications in Eqs (1) and (2). They also show the misleading results that arise from the use of dummy variables. According to the Breusch-Pagan and White test results, error terms are heteroskedastic and therefore it used generalised least squares using White's method to obtain consistent estimates of the $t$ statistics and the corresponding $p$ values. The number of observations used in each regression varies due to the data availability for related variables.

Table 1 presents also the results for benchmark bivariate regression. In each case, the logarithm of GII is regressed on one of the MSRI and MUSRATIO as well on the dummy variables MENA, ARAB, ISLAMIC and OIL. These regressions are most likely to be misspecified and are presented here in order to show that possible misleading inferences may arise. Three dummy variables, MENA, ARAB and ISLAMIC, all have positive and significant coefficients at the $1 \%$ level. The size of the coefficients are $0.32,0.23$ and 0.22 for ISLAMIC, MENA and ARAB, respectively. These estimates imply that, on average, gender equality is worse in countries with a Muslim population ratio greater than $75 \%$, in the MENA countries and ARAB countries. Indeed, on the GII scale, ISLAMIC, MENA and ARAB countries are 1.38, 1.26 and 1.25 points above the average of the other countries. Considering that the average of GII is 0.54 , these are highly significant numbers, being about 2.5 times worse. Interestingly, the MENA re- 


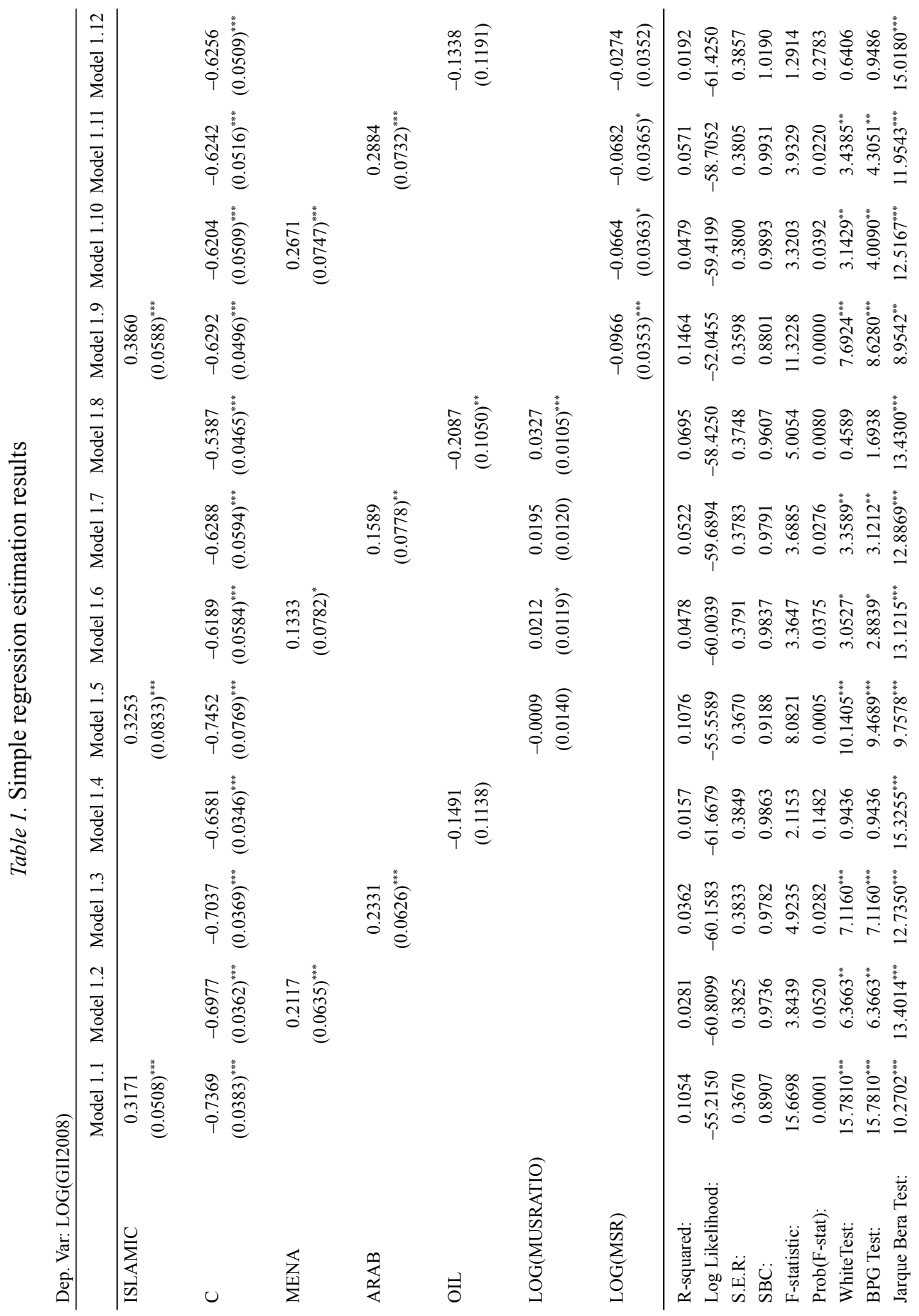


gion and Arab countries are indeed better than all the countries with a Muslim population ratio of $75 \%$ or higher. The OIL dummy is interestingly negative, although it is not significant. Thus, there seems to be no significant impact of oil on gender equality.

Table 1 also presents regressions of log GII against MUSRATIO and MSRI; with one of the ARAB, MENA, or ISLAMIC dummy variables. MUSRATIO has a positive and significant coefficient when MENA and OIL dummies are in the regression. The coefficient of MUSRATIO is negative but insignificant when the ISLAMIC dummy is in the regression and positive but insignificant when the $\mathrm{ARAB}$ dummy is in the regression. In each case, ARAB, MENA, and ISLAMIC dummy variables have positive and significant coefficients. These results imply that the Muslim population ratio has a negative impact on gender equality and that MENA, Arab- and Muslim-majority countries are worse than the average.

The Muslim population ratio can be criticized in terms of being a proxy for the extent of Islamic regulation of social life. The MSRI ranking is probably a better proxy for the Islamic religiosity of social life. The regression results given in Table I indicate that MSRI has indeed a significant and negative relationship with GII, when any of the ARAB, MENA and ISLAMIC dummy variables are present in the regression. In the case of the OIL dummy, the coefficient of MSRI is still negative but insignificant. Here, the finding is that the extent of regulation of social life by religious norms and values does not increase gender inequality, it rather reduces it. In terms of the ARAB, MENA and ISLAMIC dummy variables in the regressions with MRSI, it is again found that these have positive and significant estimates. The OIL dummy is again negative but insignificant. The findings here shed serious doubts on the use of Muslim population ratio as a proxy for the extent of Islamic regulation of social life.

As discussed previously, the regression results in Table 1 are misleading when there are other significant variables affecting gender inequality. Four variables are considered here: per capita GDP, access to and use of ICT, education and institutional quality. These regressions additionally include ARAB, MENA and ISLAMIC dummy variables and their interaction with the religion variable (MUSRATIO or MSRI). The dummy variables are included to examine whether the MENA, Arab- and Muslim-majority countries are on average different from other countries. The interaction terms capture whether the regulation of social life by Islamic norms and values have different effect on gender inequality in the MENA, Arab- and Muslim-majority countries.

Regression estimation results for when the MUSRATIO variable is used as a proxy are given in Table 2. These estimates have one result that cannot go unnoticed: the MUSRATIO variable is insignificant in all regressions, except in the case where only the OIL dummy is used and other control variables are excluded. 


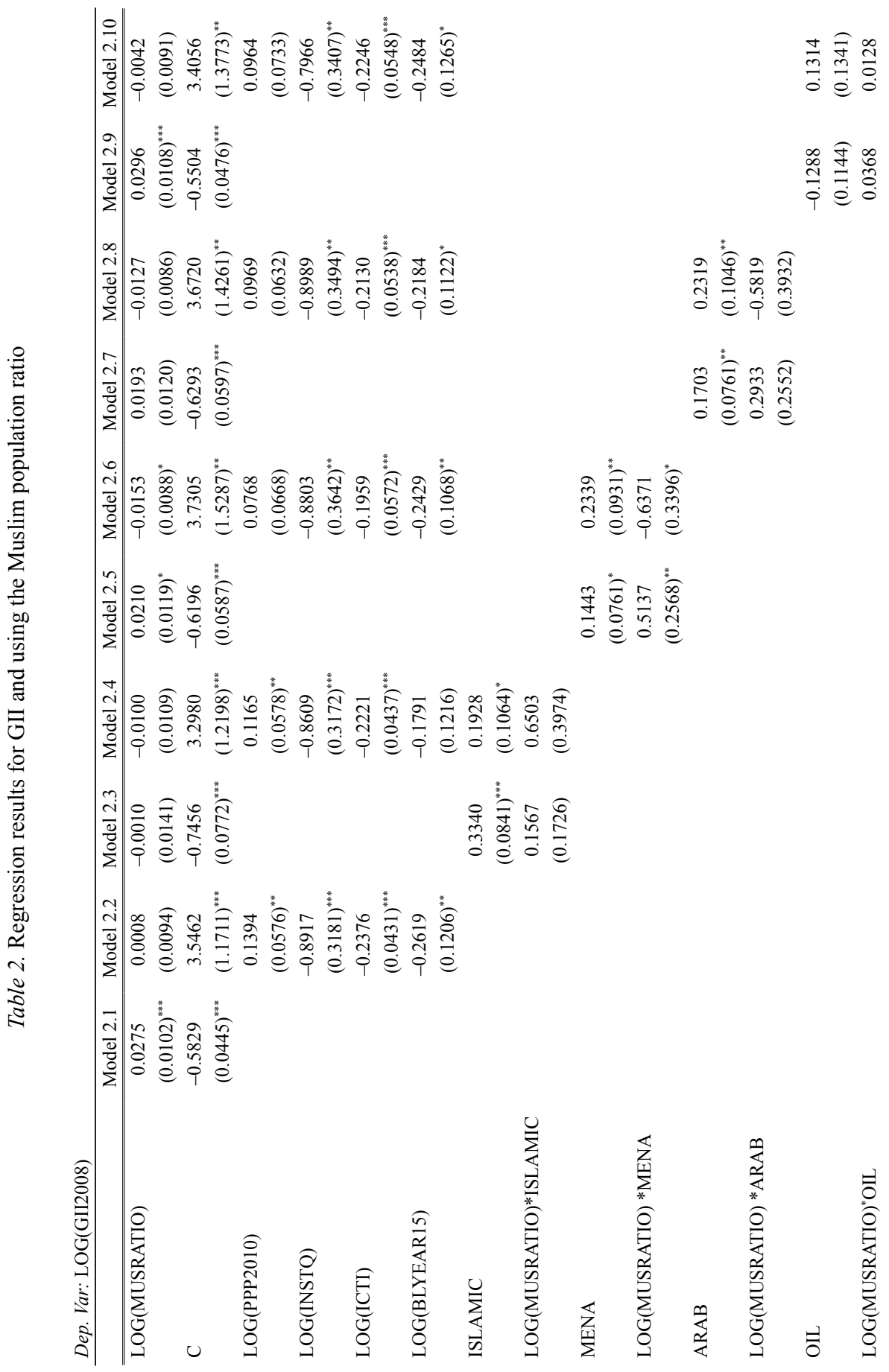




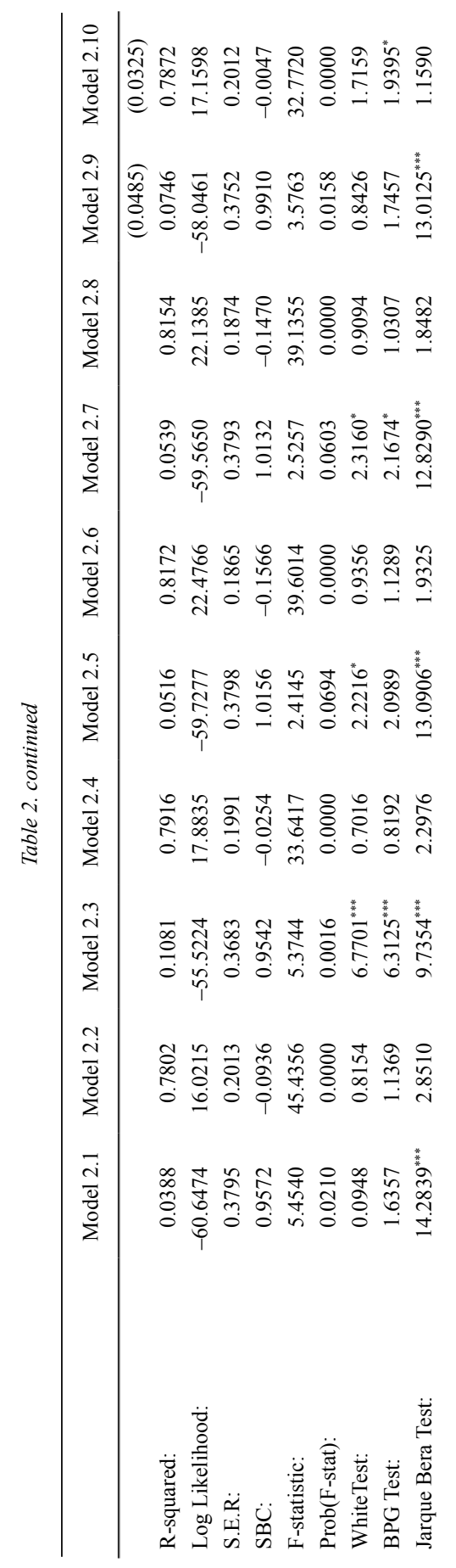


Since the regressions with excluded control variables are possibly misspecified, this exceptional regression can be ignored. Muslim population ratio is the variable most commonly used in the previous studies that found an adverse effect from this variable on gender equality. Our results certainly challenge this view. The message is clear and merits great consideration. There is no relation between gender inequality and the Muslim population ratio. What, then, accounts for gender inequality differences, if it is not religion? The results in Table 2 indicate a strong consistent negative significant relationship between gender inequality and three control variables, namely INSTQ, ICTI and BLYEAR15. Interestingly, it is found that per capita income is not related or even inversely related to gender inequality, implying that an increase in income does not help eliminate the gender gap.

In terms of interaction, Table 2 shows that the interaction of MUSRATIO with the ARAB, MENA and ISLAMIC dummy variables is negative and significant when other control variables are in the regression. The OIL interaction term is found to be insignificant. Therefore, in terms of the impact of the Muslim population ratio on gender inequality, the MENA, Arab- and Muslim-majority countries do indeed perform better than the other countries. However, the ARAB, MENA and ISLAMIC dummy variables, which capture the average of the category they represent relative to all other observations, keep their significance and adverse impact on GII. This, however, does not change the fact that a higher Muslim majority does not make the gender inequality worse; it even improves it, particularly in the MENA region.

It has been shown above that MUSRATIO is probably not a proper measure of the extent of the regulation of social life by Islamic norms and values. We believe that MSRI is based on a ranking and better represents the extent of religious regulation of social life. The regression results relating to MSRI are given in Table 3. The results in Table 3 do enhance the results in Table 1 and are more noteworthy. The most important finding is again that the MSRI coefficient is uniformly negative and sometimes even significant. This is again a clear and strong rejection of the belief that the extent of Islamic norms and values in social life has an adverse impact on gender equality. When control variables are introduced, all of the ARAB, MENA and ISLAMIC dummy variables became insignificant. Furthermore, the interaction of these variables with the Islamic regulation variable MSRI are all insignificant. The data does not support the myth that the gender gap in Muslim-majority countries is simply a result of religion, as it is often claimed. 


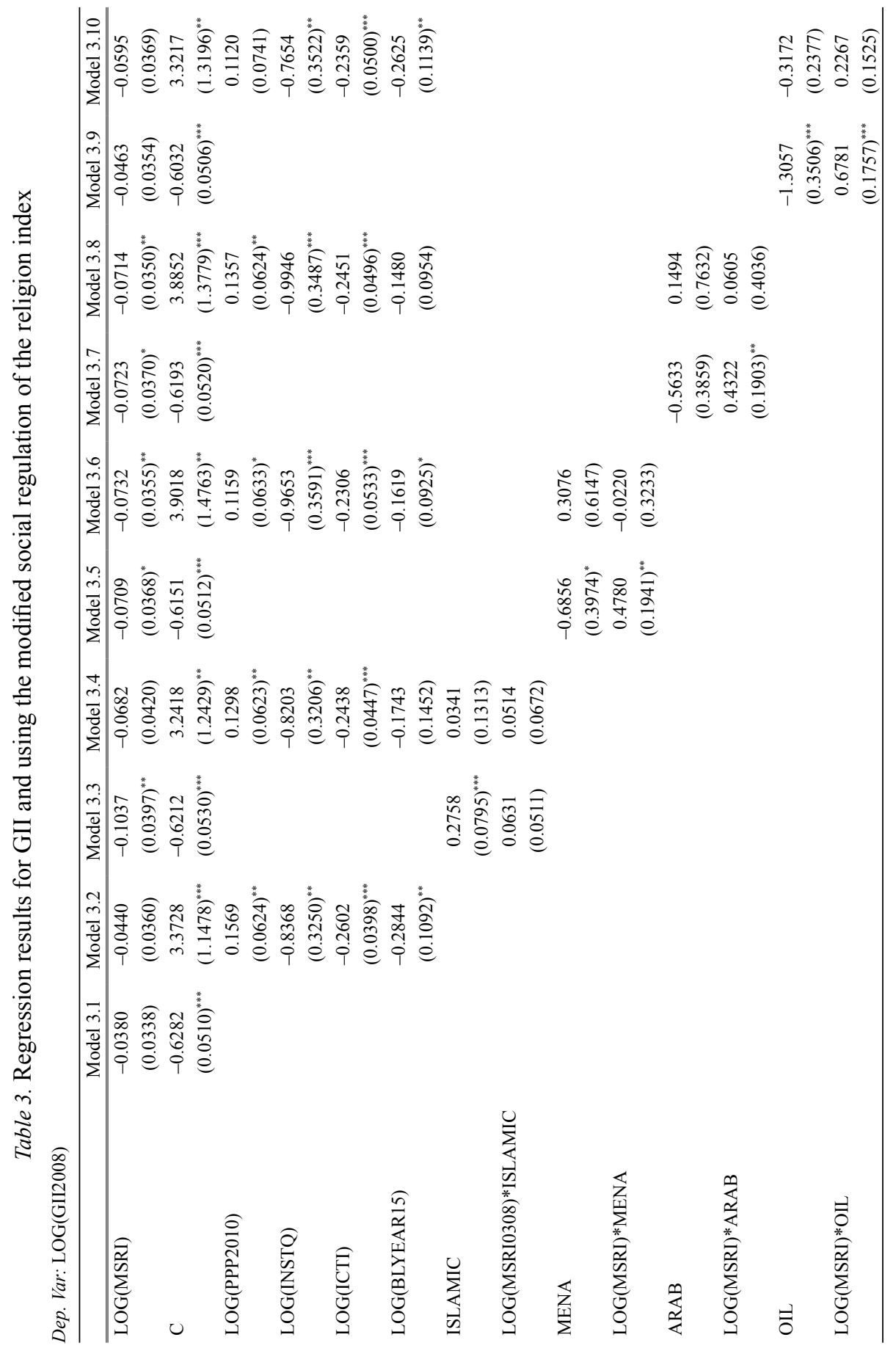




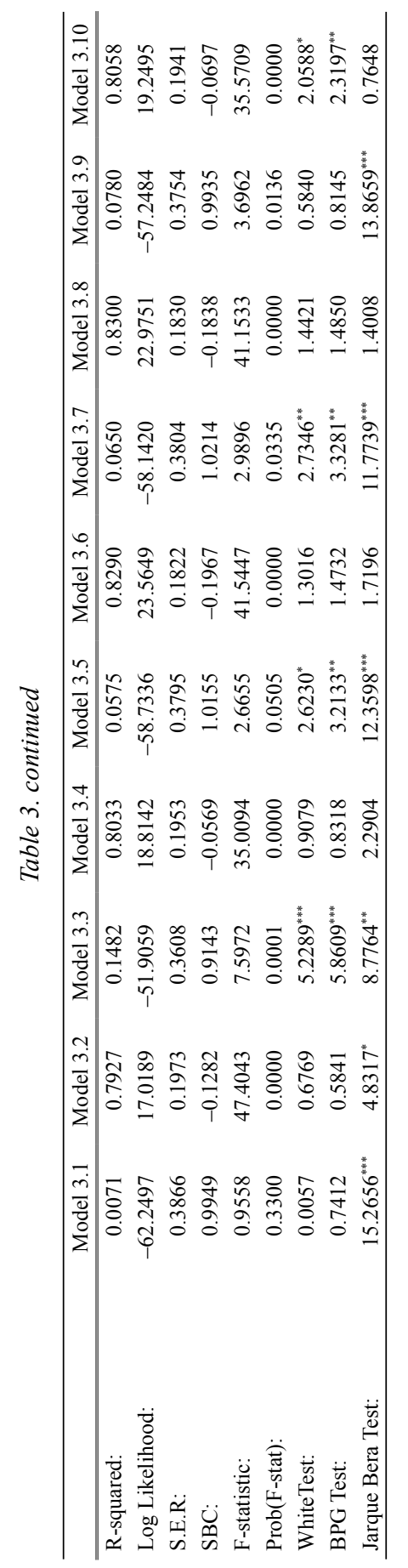




\section{CONCLUSION}

Gender equality has become a more visible issue for the Arab and, more generally, for MENA countries following the Arab Spring. Gender inequality or, more broadly, gender issues are more pronounced for the Muslim countries than in other countries and regions, usually from social, anthropological, or political aspects. Oil and religion are singled out as factors placing women of the Muslim countries in a more disadvantageous position than in other developing countries. This study examined the relationship between gender inequality in the MENA countries and, more broadly, in Muslim countries, by taking into account the impact of economic development, ICT, education, and institutions in the MENA region, and tested whether the impacts differ for the MENA countries.

The major focus of the study is to test the impact of the regulation of social life by the Islamic norms and values on gender inequality. Most studies have used gender inequality in employment and education as basic indicators of gender inequality, and usually their impact on economic growth is studied. This study considers broader measures of gender inequality and its determinants. Rather than traditional measures such as the labour force participation rate of females relative to males, the study uses the gender inequality index, which is based on variables that measure several dimensions of gender inequality. The study uses a cross-sectional dataset for 209 countries. Empirical evidence obtained in the study shows that religion only has a significant effect on gender inequality when other determinants such as the economic development, education, ICT, and institutional quality are excluded from the model. Additionally, the classification dummies for MENA, Arab- and Muslim-majority countries as well as their interaction with the religion variable are not significant. However, ICT, education and institutional quality have a significantly positive impact on gender equality, implying that improvements in these variables reduce gender inequality. No other significant difference has been found relating to religion and oil across the MENA, Arab- and Muslim-majority countries. The apparently significant religious and oil impacts disappear once institutional variables are incorporated into the regressions.

The paper obtains empirical evidence against the belief that religion and oil are the culprits responsible for holding women back in the Muslim countries. Neither of these factors fully explains the facts. Therefore, both Muslim and non-Muslim countries should develop supportive programmes that will improve the economic, social, and political empowerment of women, while simultaneously advancing democracy, laws and rights, and other socio-economic infrastructure.

Our main finding has a clear message. The core religious beliefs and culture cannot be expected to change for any given time horizon and it is difficult to 
make assumptions on the likelihood of changes. Recent developments in the Middle East have moved in unexpected directions, with increasing violence against women and children. However, gender inequality does not only relate to the strength of religion in determining how people live. The gender issue in the Muslim world is more complicated and major factors vary across countries. Institutions, cultural values, exposure to other cultures, oil, and religion do all play a role. Empirical findings do not support the simplification of gender inequality as an issue that is only linked to Islam in the Muslim countries, and doing so does not contribute to our understanding of the complicated gender dynamics in these countries.

\section{REFERENCES}

Abdelali-Martini, M. (2011): Empowering Women in the Rural Labor Force with a Focus on Agricultural Employment in the Middle East and North Africa (MENA). Expert paper prepared for the Expert Group Meeting "Enabling Rural Women's Economic Empowerment: Institutions, Opportunities and Participation", Accra, Ghana, 20-23 September 2011. http://www.un.org/ womenwatch/daw/csw/csw56/egm/Martini-EP-9-EGM-RW-Sep-2011.pdf

Brotman, S. - Katz, E. - Karnes, J. - West, W. - Irvine, A. - Daibes, D. (2008): Implementing CEDAW in North Africa and the Middle East: Roadblocks and Victories. Middle East and North Africa Report.

Donno, D. - Russett, B. (2004): Islam, Authoritarianism, and Female Empowerment: What are the Linkages? World Politics, 56(4): 582-607.

Fish, M. S. (2002): Islam and Authoritarianism. World Politics, 55(1): 4-37.

Hodgkinson, L. (2000): Is Technology Masculine? Theorising the Absence of Women. IEEE International Symposium, Rome, 8 September 2000, pp. 121-126.

Inglehart, R. - Norris, P. (2009): Muslim Integration into Western Cultures: Between Origins and Destinations. Research Working Paper Series, RWP09-007, John F. Kennedy School of Government, Harvard University.

Jacobsen, J. P. - Newman, A. E. (1995): Cherchez les Femmes? How Labor Economists Study Women. Presented at $4^{\text {th }}$ International Association for Feminist Economics Conference, Tours, France, July 5-7, 1995.

Kuçuk, N. (2013): Gender Inequality in the MENA: Myths versus Facts. Topics in Middle Eastern and African Economies, 15(2): 71-104.

Lohan, M. - Faulkner, W. (2004): Masculinities and Technologies. Men and Masculinities (Sage Publications), 6(4): 319-329.

Mason, A. D. - King, E. M. (2001): Engendering Development: Through Gender Equality in Rights, Resources, and Voice. Policy Research Report, The World bank - Oxford University Press.

Moghadam, V. (2004): Women's Economic Participation in the Middle East: What Difference has the Neoliberal Policy Turn Made? Journal of Middle East Women's Studies, 1(1): 110-146.

Noland, M. (2005): Explaining Middle Eastern Authoritarianism. Working Paper, No. 05-5, Peterson Institute for International Economics, Washington, D.C.

Rauch, J. - Kostyshak, S. (2009): The Three Arab Worlds. Journal of Economic Perspectives, 23(3): $165-188$.

Ross, M. (2008): Oil, Islam and Women. American Political Science Review, 102(1): 107-123. 
Shirazi, F. (2008): The Contribution of ICT to Freedom and Democracy: An Empirical Analysis of Archival Data on the Middle East. The Electronic Journal on Information Systems in Developing Countries, 6: 1-24.

The World Bank (2004): Gender and Development in the Middle East and North Africa Women in the Public Sphere. MENA Development Report. Washington, D.C.

The World Bank (2007): Global Monitoring Report 2007. Millennium Development Goals: Confronting the Challenges of Gender Equality and Fragile States. Washington, D.C.

The World Bank (2012): Capabilities, Opportunities and Participation: Gender Equality and Development in the Middle East and North Africa Region. A Companion Report to the World Development Report, 2012. Overview. Washington, D.C.

UNDP (2005): The Arab Human Development Report 2005: Towards the Rise of Women in the Arab World. Regional Bureau for Arab States, N.Y. USA.

UNDP (2010): Human Development Report 2010. The Real Wealth of Nations: Pathways to Human Development. $20^{\text {th }}$ Anniversary Edition. N.Y. USA. http://hdr.undp.org/sites/default/files/ reports/270/hdr_2010_en_complete_reprint.pdf

Wajcman, J. (2009): Feminist Theories of Technology. Cambridge Journal of Economics, 34(1): $143-152$. 


\section{APPENDIX}

\begin{tabular}{|c|c|}
\hline Variable & Description \\
\hline GII & Gender Inequality Index ( $0=$ no inequality, $1=$ equality $)$ \\
\hline MUSRATIO & Muslim rates (\% of total population, defined as Muslims/population) \\
\hline MSRI & $\begin{array}{l}\text { Modified Social Regulation of Religion Index, averages from 2003, } 2005 \text { and } \\
2008 \text { International Religious Freedom Reports ( } 0-10 \text {, lower is less regulation) }\end{array}$ \\
\hline PPP2010 & Gross national income per capita (PPP 2008 US \$) \\
\hline IU & Internet users (per 100 people) \\
\hline MCS & Mobile cellular subscriptions (per 100 people) \\
\hline $\mathrm{PC}$ & Personal computers (per 100 inhabitants)* \\
\hline TL & Telephone lines (per 100 people) \\
\hline UR & Urban population (\% of total) \\
\hline BLYEAR15 & Barro-Lee: Average years of total schooling, age $15+$, total \\
\hline ICTEPC & $\begin{array}{l}\text { Information and communication technology expenditure per capita } \\
\text { (current US\$) }\end{array}$ \\
\hline ICTEPGDP & Information and communication technology expenditure (\% of GDP) \\
\hline BQ & Bureaucracy quality (L) \\
\hline RR & Composite risk rating \\
\hline $\mathrm{CO}$ & Corruption $(\mathrm{F})$ \\
\hline DA & Democratic accountability $(\mathrm{K})$ \\
\hline GS & Government stability (A) \\
\hline LO & Law \& Order (I) \\
\hline ICTI & $\begin{array}{l}\text { ICT index, constructed from ICT variables by using principle components } \\
\text { analysis }\end{array}$ \\
\hline INSTQ & Institutional quality index, constructed from institutional variables \\
\hline MENA & Dummy for MENA region $(1=$ MENA, $0=$ others $)$ \\
\hline ISLAMIC & $\begin{array}{l}\text { Dummy for ISLAMIC countries, defined as MUSRATIO }>0.75 \\
(1=\text { ISLAMIC, } 0=\text { others })\end{array}$ \\
\hline ARAB & Dummy for ARAB countries $(1=\mathrm{ARAB}, 0=$ others $)$ \\
\hline OIL & Dummy for oil exporting countries $(1=$ oil exporters, $0=$ others $)$ \\
\hline
\end{tabular}

